\title{
Recombinant Adenovirus Encoding p53
}

National Cancer Institute

\section{Source}

National Cancer Institute. Recombinant Adenovirus Encoding p53. NCI Thesaurus. Code C85485.

A replication-defective, recombinant adenoviral vector encoding the wild-type human tumor-suppressor protein p53 gene with potential antineoplastic activity. Upon intratumoral administration, rAD-p53 binds to the coxsackie-and-adenovirus receptor (CAR) on tumor cells and enters cells selectively via receptor-mediated endocytosis, which may result in the overexpression of wild-type p53 intracellularly and p53-mediated tumor regression. In addition, this agent may stimulate the immune system to mount a cytotoxic T-lymphocyte (CTL) immune response against tumor cells, may activate natural killer (NK) cells to exert antitumor 'bystander effects' and may downregulate the expression of various oncogenes. The p53 protein blocks tumor cell cycle progression and directly initiates apoptosis; the p53 gene, a tumor suppressor gene, is deleted or mutated in a significant number of cancers. 